\title{
Panorama da Educação para a Prevenção do Trabalho Forçado no Brasil
}

Adonia Antunes Prado ${ }^{1}$

Luciana Siqueira da Costa $^{2}$

A Estimación Mundial sobre el Trabajo Forzoso, publicada em junho de 2012 pela OIT, (OIT 2012) indica que, em todo mundo, existem perto de 20,9 milhões de pessoas exercendo atividades econômicas que se podem classificar como tal. Estas resultam de coerção ou de engano: ausência de concordância do trabalhador; imobilização, pela existência de dívidas contraídas com o patrão ou agente a seu mando, retenção de documentos e as ameaças de denúncia às autoridades migratórias do país. Noventa por cento desses trabalhadores são explorados na economia privada e 14, 2 milhões encontram-se em atividades na agricultura, construção, trabalho doméstico, ou em manufaturas. Dados da Comissão Pastoral da Terra, publicados no caderno Conflitos no Campo 2012, informam que no Brasil, de 2003 a 2012, as atividades em que o trabalho escravo foi majoritariamente encontrado foram a pecuária (preparação de pastos) (29\%) e a cultura canavieira (27\%), dentre os casos de escravização conhecidos. Das ações de fiscalização e repressão realizadas resultaram 38.692 trabalhadores resgatados por agentes do Estado. Vale informar que é crescente a presença de casos de trabalho escravo em regiões urbanas, onde as manufaturas de roupas e a construção civil são as campeãs apresentam as maiores cifras (Canuto, Luz e Lazzarin, 2013 ou

\footnotetext{
${ }^{1}$ Professora do NEPP-DH e pesquisadora do (GPTEC) do Núcleo de Estudos de Políticas Públicas em Direitos Humanos NEPP-DH da UFRJ. adoniaprado@ hotmail.com

${ }^{2}$ Licenciada em Geografia e em Pedagogia; professora da Rede Municipal de Educação de Rio Maria (PA). lucisiquei@gmail.com
}

Brasiliana - Journal for Brazilian Studies. Vol. 2, n.2 (Nov 2013). ISSN 2245-4373. 
http://www.cptnacional.org.br/index.php/publicacoes-2/noticias-2/12-conflitos/1546conflitos-no-campo-brasil-2012.)

O Código Penal Brasileiro tipifica a situação análoga à de escravo em seu Artigo 149 e diversas têm sido as ações da sociedade civil e do Estado - estas últimas, ainda insuficientes, segundo especialistas - no sentido de coibir a existência do crime e de prevenir a ocorrência de situações a ele favoráveis. Destacam-se, dentre elas, a criação, em 1995, pelo Ministério do Trabalho e Emprego (MTE), do Grupo Especial de Fiscalização Móvel, que congrega auditores fiscais, membros do Ministério Público do Trabalho e policiais federais, com a incumbência de fiscalizar e aplicar a lei nos casos de exploração de mão de obra escrava ${ }^{3}$; sob a liderança da Secretaria de Direitos Humanos, foram produzidos dois planos nacionais de erradicação do trabalho escravo e vários planos e iniciativas dos governos estaduais. Foram criados, ainda, a Comissão Nacional para a Erradicação do Trabalho Escravo (CONATRAE), criada em 20034; o Cadastro de Empregadores - a chamada Lista Suja ${ }^{5}$ e o Pacto Nacional de Combate ao Trabalho Escravo, lançado em 2005 e firmado por empresários ${ }^{6}$; a Campanha Nacional ${ }^{7} \mathrm{e}$ campanhas setoriais de combate e prevenção, incluindo atividades de educação e de capacitação de educadores e de agentes sociais.

Diante deste quadro, atualmente vêm sendo desenvolvidos diversos tipos de ações educativas de combate e prevenção do trabalho escravo no Brasil: a) algumas campanhas visam ao esclarecimento de trabalhadores envolvidos e vulneráveis a

\footnotetext{
${ }^{3}$ Ver http://portal.mte.gov.br/trab_escravo/grupo-de-fiscalizacao-movel.htm

${ }^{4}$ Ver:http://www.sdh.gov.br/assuntos/combate-ao-trabalho-escravo/programas/comissao-nacional-para-aerradicacao-do-trabalho-escravo

${ }^{5}$ Cadastro criado pelo Ministério do Trabalho e Emprego que apresenta os nomes das empresas flagradas na prática do crime de exploração de mão de obra escrava, disponível em http://portal.mte.gov.br/portal-mte/ .

${ }^{6}$ Ver http://reporterbrasil.org.br/documentos/pacto/folder_pacto.pdf

${ }^{7}$ Consultar http://www.oit.org.br/sites/all/forced_labour/brasil/iniciativas/campnac/index.htm
} 
situações de trabalho escravo ou análogas às mesmas, outras ao público em geral; b) outras oferecem escolarização, capacitação e subsequente colocação profissional a trabalhadores resgatados do trabalho escravo por meio de operações realizadas por órgãos do Estado, bem como a populações consideradas vulneráveis; c) há cursos e capacitações destinados a professores e professoras de redes públicas de ensino e a lideranças locais e estão voltadas para a formação de sujeitos multiplicadores do trabalho de divulgar e prevenir futuras situações de risco, dado que se encontram atuando com a população infantil e juvenil e suas famílias, em municípios onde se tem encontrado um número significativo de moradores que migram para trabalhar e findam por cair em situações de escravidão; d) outras ações são dedicadas a crianças, jovens e estudantes de turmas de Educação de Jovens e Adultos.

As ações são realizadas atividades educativas por meio de parcerias entre instituições do Estado e da sociedade civil, como ONG, empresários, operadores da justiça, das entidades da sociedade que atuam por conta própria, dentre outros sujeitos. Por meio delas se pretende modificar formas de pensar e agir em relação à realidade social, buscando-se transformar características culturais contidas nas relações de trabalho que, muitas vezes, levam a que se percebam como "naturais" as formas de utilização da mão de obra de trabalhadores e trabalhadoras que desrespeitam direitos legais e legítimos, pois se entende que "sempre foi assim". E, ainda, que se trabalhe no sentido de contribuir para o empoderamento - por meios formais e informais de educação - de atores sociais tradicionalmente negligenciados pelos agentes do Estado.

Entretanto, parece necessário refletir teoricamente sobre: 1. o papel da educação formal e/ou informal, difusa - e sua viabilidade - no combate e na prevenção a de tais crimes; 2 a ideia de que ações educativas podem contribuir para mudar a realidade e 3. o caráter educativo de campanhas em jornais, revistas, por meio de banners ou peças de divulgação veiculadas via internet ou mesmo palestras ou outras ações pontuais. 
Tomando-se este conjunto de interrogações, neste momento se está considerando as diferentes ações arroladas até agora como atos educativos com potencial para enfrentar e combater a presença do trabalho escravo no Brasil e, para tanto trabalha-se com o entendimento da educação como processo social capaz de traduzir, propor e contribuir para a consolidação de formas de pensar e agir de acordo com interesses e necessidades postos por diferentes grupos sociais. Entende-se que o ato educativo tem qualidade e intenção ideológicas, percebidas as ideologias aqui como visões de mundo, representações do viver em sociedade oriundas de experiências de inserção social daqueles sujeitos educativos e/ou de opções feitas intelectual e conscientemente a partir de adesão ético-política.

\section{Educação: natureza e compromisso}

De início, faz-se necessário uma reflexão a respeito de como estão sendo considerados pelos educadores os diferentes atores implicados nos processos educativos em pauta e a que tipo de atores sociais dirigem suas ações. É necessário discutir e entender de que maneira estes atores percebem o papel da educação em tais processos sendo, neste momento, importante ter clareza a respeito do como cada sujeito percebe o outro ator que é seu interlocutor. Por exemplo, em que bases se dão a relação professor-aluno nas aulas, qual é a expectativa de um frente ao outro e de ambos em relação àquela ação, aos agentes que a estão promovendo, às instituições do Estado e da sociedade civil e em que medida o ato de educar associa a educação laboral á educação para a cidadania?

Um dos compromissos destacados nesta pesquisa desde que foram escritas suas primeiras linhas foi chamar atenção para o que "socialmente" se considera como sendo o papel da educação na nossa realidade. Terá este processo social a varinha mágica capaz de resolver todos os problemas que afligem e perturbam o cotidiano: da violência 
ao consumo de drogas ilícitas (quanto ao consumo de drogas lícitas nada se comenta), da destruição ambiental à violência no trânsito, da falta de mão de obra capacitada para atender aos "desafios do desenvolvimento" às péssimas escolhas eleitorais etc.

É claro que esta pesquisa não pretende abarcar tão ampla gama de temas, mas em relação às ações educativas voltadas ao combate e prevenção do trabalho escravo no Brasil, pode-se propor que as mesmas sejam vistas como frentes de trabalho comprometidas com a consolidação de uma cultura verdadeiramente cidadã, pautada no respeito aos direitos humanos, operando uma pedagogia popular (interativa, participativa, sensível às diferentes realidades e necessidades dos trabalhadores) na qual temáticas, metodologias, recursos pedagógicos etc. estejam em consonância com seus objetivos centrais.

No dizer de Arroyo (1987), comentando a centralidade que a educação adquire na sociedade moderna, ela passa a ser encarada como o santo remédio contribuindo, tanto para a libertação, como para a opressão. O pensamento liberal, muitas vezes traduzido em senso comum em nossa sociedade, espera da educação o milagre de configurar o novo homem livre para o novo mercado econômico social e político. (pp. 36-37)

A centralidade atribuída aos processos educacionais, desta maneira, passa a ser o modo privilegiado de substituir formas sociais arcaicas por novos padrões sociais, de alguma maneira, constrói-se a ideia de modernidade criando-se uma relação invertida com situações que a sociedade deveria superar. Criticamente, Arroyo afirma que, segundo esta perspectiva, "Somente será reconhecido como apto a participar como sujeito social e político quem tiver vencido a barbárie, a ignorância, quem tiver aprendido a nova racionalidade, quem tiver sido feito homem moderno (1987, p. 37). Também se poderia citar aqui De Freitas: o que falta no outro é tudo o que nele supostamente éabundante. (2005, p. 20) 
Tamanha apologia (ingênua) da educação parece favorecer o surgimento de duas questões: a primeira está relacionada ao fato de que o exagero na valorização positiva da construção do "novo", do "agora", do moderno, leva ao risco de se ocultar ou esquecer que nele também se encontram mazelas - as próprias e a ela inerentes - e aquelas residuais, herdadas nos velhos modelos; a segunda estaria em que se a educação direcionada aos sujeitos em busca de justiça, dignidade e reconhecimento de seus direitos humanos e de sua cidadania, não operar de outra maneira, se ela não tiver um sentido popular e democrático, em termos de forma e de conteúdo, de nada valerão os empreendimentos e mobilizações que têm sido realizados - investimentos pesados, em termos profissionais, emocionais, políticos etc. como se poderá observar, em parte, neste trabalho.

Ainda em relação às ideias salvacionistas e, com certeza, bem intencionadas, destacase o risco de se trabalhar com o pressuposto, seguramente inconsciente e oriundo de possível incompreensão a respeito na natureza do próprio processo que se está propondo, de que se esteja contribuindo para a regeneração de um "outro", um outro rude, no dizer de Marcos Cezar de Freitas. Atrasado, bruto, incapaz até mesmo de lutar por sua sobrevivência e por sua liberdade, passivo em meio às vicissitudes gerais. ${ }^{8}$

Mais uma vez há que se afirmar que a educação solidária e popular deve operar com parâmetros diversos daqueles da educação liberal e bancária, na expressão de Paulo Freire. É preciso ir além dos modelos conservadores, denunciados desde os anos 1920 no Brasil e até hoje hegemônicos na educação formal e, em muitos casos, em práticas informais, não escolares, também. Elas reproduzem o que Madan Sarup denomina como

\footnotetext{
8 "Tanto quando são produzidas como quando são apropriadas e usadas, as representações do rústico e da rusticidade tornam-se armas poderosas em decorrência dos vínculos que adquirem com as estratégias de dominação econômica." De Freitas, 2005, p. 21.
}

Brasiliana - Journal for Brazilian Studies. Vol. 2, n.2 (Nov 2013). ISSN 2245-4373. 
condições do capitalismo, nas quais a educação é realizada em circunstâncias tão alienantes que se torna um processo de desumanização (1980, p. 117).

A este respeito, Dermeval Saviani, (1991), entende a educação como um momento de construção da humanidade do homem, o que só pode acontecer no coletivo, no bojo de relações sociais, no território mesmo onde a história dos homens e mulheres tem lugar. Saviani afirma que

o que não é garantido pela natureza tem que ser produzido historicamente pelos homens... consequentemente, o trabalho educativo e o ato de produzir, direta e intencionalmente, em cada indivíduo singular, a humanidade que é produzida histórica e coletivamente pelo conjunto dos homens. ( p. 21)

A educação popular não pode ser colonialista, tem que ser dialógica e respeitosa das identidades outras envolvidas no processo. Tem que ter em seu horizonte a noção de que

Ensinar não é transferir conhecimento, mas criar as possibilidades para a sua própria produção ou a sua construção e de que o educador ou educadora progressista, que não pode nem deve se omitir, ao propor a sua 'leitura de mundo' [deve] salientar que há outras 'leituras de mundo', diferentes da sua e às vezes antagônicas a ela (Freire, 1992, pp. 112-113).

Deve respeitar sua expressão, acolhê-la, acolhendo, assim, na diversidade as diferentes realidades (culturais, étnicas, de gênero etc.) trazidas pelos educandos. 
Observa-se o caráter educativo das campanhas e demais ações arroladas por este estudo, visto que nelas encontram-se os mais importantes e característicos elementos de tais práticas: têm como objetivo a informação e a informação de destinatários mais ou menos identificados, dependendo do nível de formalidade e da intensidade ou de difusão do foco empregado por seus agentes. Atuam por meio de metodologias e recursos materiais específicos, escolhidos e/ou criados com o objetivo de reproduzir ou modificar comportamentos, disposições e visões de mundo.

As instituições envolvidas em ações educativas visando à prevenção e, em última instância, à erradicação do trabalho forçado no Brasil fazem, por meio de suas intervenções um trabalho que expõe e afirma a proximidade entre os conceitos de educação e de ideologia. Educação não restrita aos espaços que Althusser denominou como aparelhos ideológicos do Estado(s/d), até por que não se opera aqui com a noção de que as práticas ideológicas tenham exclusivamente sua origem nos interesses e necessidades das classes dominantes, ou que produzam apenas falsa consciência ou versões invertidas da realidade. A opção aqui é pensar as práticas de educação para a promoção e o resgate da humanidade de trabalhadores libertados de situações extremas de exploração e expropriação material e simbólica como projetos orientados por utopias e ideologias nascidas e alimentadas nos embates de setores da sociedade civil - algumas vezes apoiadas por atores do Estado solidários com a militância resistente - em busca de justiça e reconhecimento de direitos.

O trabalho educativo se dá por meio de múltiplas e diferentes formas simbólicas (ideológicas), buscando sentido no universo daqueles sujeitos ou, no entender de Gramsci, elaborando e explicitando os princípios potencialmente criativos que estão implícitos na compreensão prática dos oprimidos... (Thompson, 1998; Eagleton, 1994, p. 199 e Gramsci, 2001).

Brasiliana - Journal for Brazilian Studies. Vol. 2, n.2 (Nov 2013). ISSN 2245-4373. 
São ações que operam em um campo em que diferentes visões de mundo disputam espaço em corações e mentes, interessadas em contribuir com a criação e consolidação de visões de mundo, de modos de pensar e de agir identificados com as populações atingidas, com suas práticas próprias de reagir e de se fazer respeitar, muitas vezes invisíveis até por seus aliados. São lugares onde também se expressam as contradições da sociedade inclusiva, onde é e será sempre necessário avaliar e rever ações e concepções, mas ainda assim, lugares onde se busca construir a cidadania e os direitos humanos de milhares de trabalhadores.

Pelo momento, tais considerações não serão desenvolvidas. Até por que a vocação deste texto é a do destaque a ações que afirmam a dignidade e os direitos cidadãos de milhares de trabalhadores brasileiros expostos à humilhação e ao sofrimento por atores sociais que clamam por "liberdade, igualdade e fraternidade" ideologicamente liberais, mas autores de práticas laborais coloniais. Este é o momento, sim, de destacar a atuação de educadores e educadoras que trabalham pela bandeira dos direitos humanos e da justiça social, colocando em prática uma educação partidária da luta dos mais pobres, fazendo a crítica de suas pedagogias na própria prática, procurando atingir - e é ainda Sarup (1980) quem afirma - o necessário para superar a alienação é não somente a crítica, mas ação social também.

\section{Algumas ações de educação para a prevenção do trabalho forçado no Brasil}

A escolha dos casos em pauta neste artigo deve-se à maior regularidade das mesmas, da tendência para o crescimento de algumas delas e da variedade de sujeitos - educadores e educandos - envolvidos nos processos educativos. Alcançar o universo do que se faz a respeito no vasto território brasileiro pareceria uma bonita utopia, mas um objetivo praticamente inalcançável, pois a realidade é "incapturável", com o perdão do 
neologismo e, permanentemente, mutante ${ }^{9}$. Fez-se necessário, portanto, extrair algumas situações de um leque mais amplo ${ }^{10}$.

Este texto trata de cinco experiências de educação para a prevenção da exploração de mão de obra forçada no Brasil, eleitas como um recorte de um universo mais amplo que contempla outras campanhas e ações passíveis de serem ou terem sido tão regulares e institucionalizadas quanto as que serão comentadas a seguir. Outras, ainda, são ações que não acontecem regularmente e dependem da realização de situações favoráveis como, por exemplo, a oportunidade de que um determinado grupo de destinatários (operadores do direito, para citar um deles) esteja disponível em uma determinada ocasião em que se pretende realizar a ação. Ou, ainda, a possibilidade de se ter, em uma determinada data, levantado o montante de recursos necessários para a efetivação da atividade. Parece, ainda, oportuno explicitar que as pesquisadoras não pretenderam realizar um senso de tais ações, mas colher informações a respeito daquelas mais significativas e estudá-las. Como referido anteriormente, a pesquisa a que este artigo se refere encontra-se em curso. O conjunto das análises vem sendo processado, alimentado, criticado internamente e, também, em diálogo desenvolvido com os sujeitos em questão.

A primeira das ações aqui mencionadas, intitulada Projeto de Qualificação Integrada, é uma iniciativa da equipe da Superintendência Regional do Ministério do

\footnotetext{
${ }^{9}$ Ver Anexo.

10 Além das ações em pauta, encontra-se no arquivo do GPTEC documentação relativa aos seguintes programas/projetos: Movimento Ação Integrada, a cargo do Sindicato Nacional dos Auditores Fiscais do trabalho (Brasília DF); Vozes da liberdade, programa radiofônico transmitido pela ONG Repórter Brasil (São Paulo); Vozes da esperança, programa radiofônico transmitido por rádio comunitária na cidade de Açailândia (MA); Que trabalho é esse?", coletânea de filmes curtos televisionados em trens da Companhia Vale do Rio Doce, empresa mineradora brasileira, contada entre as maiores do mundo (Região Norte do Brasil); Trabalho escravo contemporâneo: longe elou perto de nossos olhos, projeto de extensão universitária desenvolvido pela equipe do GPTEC/NEPP/DH/UFRJ desde 2007 e o Projeto Oficina sobre o trabalho decente e a coletivização do processo, proposta pela CONATRAE . Com base nestas fontes foi organizado um pequeno banco de dados com informações sobre responsáveis pelo projeto/programa, parceiros, fonte de recursos, objetivos, justificativa, metodologia, público alvo, abrangência e resultados esperados.
}

Brasiliana - Journal for Brazilian Studies. Vol. 2, n.2 (Nov 2013). ISSN 2245-4373. 
Trabalho e Emprego do Mato Grosso que arregimenta trabalhadores resgatados em operações de fiscalização e, também, populações em situação de vulnerabilidade frente a este tipo de crime, ou seja, trabalhadores rurais sem terra, com pouca ou nenhuma escolaridade, moradoras em regiões com baixos índices de desenvolvimento humano, dentre outras condições favoráveis à prática do trabalho escravo. O projeto teve início em 2009 e em 2013 assumiu âmbito nacional, a partir de deliberação tomada pelo Sindicato Nacional dos Auditores Fiscais do Trabalho (SINAIT), agora sob a denominação Movimento Ação Integrada (Projeto de Qualificação Ação Integrada, 2009, e Movimento de Ação Integrada, 2012).

O Programa de Prevenção do Trabalho Escravo e Inclusão Educacional de Cidadãos Resgatados no Município de Açailândia (MA), com existência entre 2008 e 2010, foi desenvolvido pela empresa Viena Siderúrgica S/A, após a operação realizada por agentes do governo brasileiro que encontraram evidências de trabalho escravo em sua cadeia produtiva. As ações do Programa eram destinadas a educadores que ofereciam elementos de alfabetização a jovens e adultos em situação de vulnerabilidade social ou egressa do trabalho escravo no município de Açailândia buscando integrá-los, em seguida, a turmas regulares da Rede Municipal de Educação (Programa de Prevenção do Trabalho Escravo e Inclusão Educacional de Cidadãos Resgatados [2009]) e http://www.alfabetizacao.org.br/site/noticia.asp?id=731).

A ONG Repórter Brasil desenvolve o Programa Escravo, nem pensar! Criado em 2004, junto a educadores, lideranças comunitárias e demais agentes sociais com potencial multiplicador nas comunidades às quais o Programa se dirige. Este programa trabalha na perspectiva da Educação Popular freireana e sua metodologia de trabalho é diversificada e se desdobra para além dos cursos de formação, incluindo projetos comunitários, concursos, a produção de cartilhas, dentre outros elementos (Escravo, 
Nem Pensar! Uma abordagem sobre Trabalho Escravo Contemporâneo na Sala de Aula e na Comunidade, 2012).

O Projeto Trilhas da Liberdade, a cargo da Catholic Relief (CRS), ligada à Conferência Católica de Bispos dos Estados Unidos, é desenvolvido desde 2004, em conjunto com uma rede de instituições nacionais, atua em áreas de maior incidência de trabalho escravo, e, especial Amazônia Legal e Nordeste, visando à educação e à socialização de trabalhadores/as, na linha da geração de trabalho e renda e economia solidária, visando à autonomização de sujeitos e populações vulneráveis (http://portal.mte.gov.br/delegacias/pi/lancamento-do-projeto-trilhas-da-liberdade.htm). A seguinte ação é desenvolvida pela Comissão Pastoral da Terra (CPT) desde 1997 e intitula-se De Olho Aberto Para Não Virar Escravo e tem um alter-ego que é a Campanha Nacional de Combate ao Trabalho Escravo, também da CPT. Esta ação também está voltada às populações vulneráveis a situações de escravização de trabalhadores e trabalhadoras rurais e tem nos seus agentes a principal equipe de educadores. Esta campanha tem o duplo caráter de combater e prevenir a escravização de trabalhadores rurais no momento em que acolhe e encaminha denúncias da prática do crime e ao mesmo tempo desenvolve práticas de educação popular voltadas para a criação de sujeitos críticos. Dirige-se a educadores, crianças, jovens e adultos multiplicadores, entidades representativas dos trabalhadores e público em geral ${ }^{11}$

\section{Considerações finais}

A escolha destas iniciativas obedeceu ao interesse de apresentar experiências desenvolvidas por diferentes sujeitos sociais que, segundo a ordem em que são

11 Ver: http://www.cptnacional.org.br/index.php/campanhas/campanha-de-combate-ao-trabalho-escravo e http://www.cptnacional.org.br/index.php/component/content/article/6-trabalho-escravo-/trabalho-escravo-/195campanha-de-prevencao-e-combate-ao-trabalho-escravo

Brasiliana - Journal for Brazilian Studies. Vol. 2, n.2 (Nov 2013). ISSN 2245-4373. 
apresentadas, são: agentes do Estado, empresariado, organização não governamental, agência de cooperação internacional e entidade da Igreja Católica.

Em comum todas explicitam o objetivo de combater e prevenir o trabalho forçado no Brasil. De forma particular verificam-se diferenças quanto aos objetivos declarados, que podem ser de formar para a cidadania; para o entendimento dos diferentes aspectos que conformam o caldo do qual brotam as condições para a prática da escravização; uma convocação para a produção de resistências, que podem situar-se no desmascaramento do aliciador no momento do convite ou no incentivo à denúncia de situações existentes conhecidas ou para a inserção no mercado de trabalho. O objetivo de uma campanha, em alguns casos é o de criar condições de empregabilidade para o trabalhador libertado ou para pessoas em situação vulnerável - alfabetização mais profissionalização. Em outros, também se voltam para a libertação pela geração de renda, não necessariamente por meio de emprego, mas através do engajamento em atividades de economia solidária, de aproveitamento de materiais de uso tradicional para a produção e venda. Enfim, pode-se observar que as finalidades estão razoavelmente afinadas, mas as estratégias e concepções do que vem a ser a educação visando ao combate e à prevenção do trabalho forçado variam, dependendo do compromisso social, das concepções de educação e de mundo, da vocação e do engajamento das entidades que colocam tais programas e projetos em prática. E podem ser analisadas e melhor conhecidas, também, por meio, da maneira como os diversos sujeitos se representam e representam as relações que entre si se estabelecem.

O atual estágio de desenvolvimento deste estudo mostra que é cara a noção de que as diferentes práticas educativas mostram características que vão além do meramente pedagógico. São diferentes formas de conceber e orientar as práticas educativas de modo a produzir novas formas de sociabilidade entre os seres humanos ou, de outra maneira, reproduzir aquelas já conhecidas e praticadas. Acrescente-se a isto 
que os elementos da cultura, associados às relações e interesses econômicos presentes, o histórico de relações sociais que se estabelecem em cada situação nas diferentes realidades nas quais se dão as situações estudadas e sobre as quais o estudo se debruça, podem temperar as possibilidades de entendimento que este estudo venha a produzir sobre a realidade vivida.

Se educar é favorecer, é instrumentar ideologias, entendidas como formas de pensar, de entender a vida e o mundo da vida, espera-se que a melhor percepção de como se desenvolvem os projetos subjacentes e as práticas vivenciadas nos processos educativos venham a contribuir para o aprimoramento da luta contra as práticas do trabalho escravo no Brasil dos dias atuais. A apresentação deste "panorama" pretende representar mais um passo, dentre outros vindouros, com os quais pretende-se trazer mais luz ao entendimento do papel da educação no quadro das diversas ações sociais de combate à escravidão contemporânea no Brasil.

\section{Bibliografia}

Alfabetização Solidária. Programa de prevenção do trabalho escravo e inclusão educacional de cidadãos resgatados. São Paulo: 2009. (Inédito).

Althusser, Louis. Ideologia e aparelhos ideológicos do Estado. Lisboa: Presença, n/d.

Arroyo, Miguel. G. Educação e exclusão da cidadania. Em Buffa, E.,Arroyo, M. G. \& Nosella. P. (Eds.). Educação e cidadania: quem educa o cidadão? São Paulo: Cortez e Autores Associados, 1987, pp. 31-80

Comissão Pastoral da Terra.(CPT)

http://www.cptnacional.org.br/index.php/campanhas/campanha-de-combate-aotrabalho-escravo e

http://www.cptnacional.org.br/index.php/component/content/article/6-trabalhoescravo-/trabalho-escravo-/195-campanha-de-prevencao-e-combate-ao-trabalhoescravo).

Brasiliana - Journal for Brazilian Studies. Vol. 2, n.2 (Nov 2013). ISSN 2245-4373. 
Canuto, Antônio; Luz, Cássia Regina da Silva e Lazzarin, Flávio. Conflitos no Campo Brasil 2012. Goiânia: CPT Nacional - Brasil, 2013.

De Freitas, Marcos Cezar. Alunos rústicos, arcaicos \& primitivos. O pensamento social no campo da educação. São Paulo: Cortez Editora, 2005.

Eagleton, T. A ideologia e suas vicissitudes no marxismo ocidental. In: Zizek, Slavoj. (Org.). Um mapa da ideologia. Pp. 179-226. Rio de Janeiro: Contraponto, 1994, pp. 179-226).

Escravo, nem pensar! Uma abordagem sobre trabalho escravo contemporâneo na sala de aula e na comunidade. 2 ed atualizada. São Paulo: Repórter Brasil, 2012.

Freire, Paulo. Pedagogia da esperança. (5 ed.). Rio de Janeiro: Paz e Terra, 1992.

Gramsci, Antonio. Caderno 12. Apontamentos e notas dispersas para um grupo de ensaios sobre a história dos intelectuais. In: Coutinho, C. N. (Ed.) Cadernos do cárcere. Vol. 2. Rio de Janeiro: Civilização Brasileira, 2001. Pp. 13-54.

International Labor Organization. ILO. Global Estimate of Forced Labour 2012: Results and Methodology.Disponível em : < OIT Trabajo forzoso 2012 wcms_182010.pdf. >Acesso em 10/08/2013.

Sarup, M. Marxismo e educação. Rio de Janeiro: Zahar, 1980.

Projeto de Qualificação Ação Integrada. Cuiabá: Superintendência Regional do Trabalho e Emprego em Mato Grosso, 2009.

Saviani, Dermeval. Pedagogia histórico-crítica. Primeiras aproximações. São Paulo: Cortez e Autores Associados, 1991.

Projeto trilhas da liberdade.

http://portal.mte.gov.br/delegacias/pi/lancamento-do-projeto-trilhas-da-liberdade.htm

Sindicato Nacional dos Auditores Fiscais do Trabalho SINAIT. Movimento Ação Integrada por uma ação ativa na reinserção social dos egressos e vulneráveis ao trabalho escravo contemporâneo. Brasília: Movimento Ação Integrada; OIT e SINAIT, 2012. 
Thompson, John. B. Ideologia e cultura moderna. 2. Ed. Rio de Janeiro: Vozes, 1998.

\section{Anexo}

Algumas campanhas e ações educativas de combate e prevenção ao trabalho escravo contemporâneo - Brasil - 2013

\begin{tabular}{|c|c|c|c|}
\hline Título & Responsável & Objetivos & Público Alvo \\
\hline $\begin{array}{l}\text { Projeto de } \\
\text { Qualificação Ação } \\
\text { Integrada }\end{array}$ & $\begin{array}{l}\text { Superintendênci } \\
\text {-a Regional do } \\
\text { Trabalho e } \\
\text { Emprego em } \\
\text { Mato Grosso - } \\
\text { SRTE-MT }\end{array}$ & $\begin{array}{l}\text { Criar condições e propor iniciativas juntos } \\
\text { as instituições privadas, públicas e } \\
\text { sociedade civil que promovam } \\
\text { modificação social, educacional e } \\
\text { econômica dos trabalhadores retirados do } \\
\text { T.E. e/ou em situação de vulnerabilidade } \\
\text { dispostas e aptas a participar dos cursos de } \\
\text { qualificação técnico-educacional ofertados } \\
\text { pelas empresas do estado. Reinserção e } \\
\text { prevenção, e a informação e capacitação } \\
\text { possibilitando assim a autonomia efetiva } \\
\text { dos egressos. }\end{array}$ & $\begin{array}{l}\text { Egressos do T.E. } \\
\text { e/ou em situação } \\
\text { de vulnerabilidade }\end{array}$ \\
\hline $\begin{array}{l}\text { Viena Educar: } \\
\text { programa de } \\
\text { Prevenção do } \\
\text { Trabalho Escravo e } \\
\text { Inclusão Educacional } \\
\text { de Cidadãos } \\
\text { Resgatados no } \\
\text { Município de } \\
\text { Açailândia (MA), por } \\
\text { meio da Educação de } \\
\text { Jovens e Adultos. }\end{array}$ & \begin{tabular}{|l|} 
Viena \\
Siderúrgica S/A \\
(Responsável \\
Financeiro) e \\
Conselho Gestor \\
(Responsável \\
Pedagógico)
\end{tabular} & $\begin{array}{l}\text { Além do objetivo geral de prevenir } \\
\text { ocorrências de trabalho forçado na região } \\
\text { onde está localizado, o programa declara } \\
\text { como objetivos específicos: realizar cursos } \\
\text { de Alfabetização Contextualizada; } \\
\text { capacitar alfabetizadores das comunidades } \\
\text { atendidas, no que concerne à metodologia } \\
\text { da alfabetização e a temática do trabalho } \\
\text { escravo; fomentar a oferta pública de } \\
\text { educação continuada de jovens e adultos; } \\
\text { realizar ações de fortalecimento } \\
\text { institucional local para a prevenção ao } \\
\text { trabalho escravo. }\end{array}$ & $\begin{array}{l}\text { Professores } \\
\text { alfabetizado-res } \\
\text { que atuarão junto } \\
\text { a trabalhadores } \\
\text { egressos do } \\
\text { trabalho escravo. }\end{array}$ \\
\hline
\end{tabular}

Brasiliana - Journal for Brazilian Studies. Vol. 2, n.2 (Nov 2013). ISSN 2245-4373. 


\begin{tabular}{|c|c|c|c|}
\hline $\begin{array}{l}\text { Escravo, Nem } \\
\text { Pensar! }\end{array}$ & $\begin{array}{l}\text { Organização } \\
\text { Não } \\
\text { Governamental } \\
\text { Repórter Brasil }\end{array}$ & $\begin{array}{l}\text { Criado em atendimento às demandas do } \\
\text { Plano Nacional para a Erradicação do } \\
\text { Trabalho Escravo, tem como objetivos: } \\
\text { diminuir, por meio da educação, o número } \\
\text { de trabalhadores das regiões Norte, } \\
\text { Nordeste e Centro-Oeste aliciados para o } \\
\text { trabalho escravo na Amazônia e no } \\
\text { Cerrado brasileiros; difundir o } \\
\text { conhecimento a respeito de tráfico de } \\
\text { pessoas e de trabalho escravo rural } \\
\text { contemporâneo como forma de combater } \\
\text { essa violação dos direitos humanos; e } \\
\text { promover o engajamento de comunidades } \\
\text { vulneráveis na luta contra o trabalho } \\
\text { escravo. }\end{array}$ & $\begin{array}{l}\text { Composto por } \\
\text { professores, } \\
\text { professoras, } \\
\text { gestores e gestoras } \\
\text { da Educação e } \\
\text { lideranças } \\
\text { populares, } \\
\text { escolhidos por } \\
\text { conta de seu perfil } \\
\text { multiplicador. }\end{array}$ \\
\hline Trilhas da Liberdade & $\begin{array}{l}\text { Cáritas Regional } \\
\text { do Piauí, } \\
\text { FETAG-PI, } \\
\text { Serviço Pastoral } \\
\text { do Migrante e a } \\
\text { Delegacia } \\
\text { Regional do } \\
\text { Trabalho do } \\
\text { Estado do Piauí. }\end{array}$ & $\begin{array}{l}\text { O projeto Trilhas da Liberdade tem como } \\
\text { objetivo promover a capacitação e } \\
\text { formação do trabalhador resgatado da } \\
\text { situação de escravidão ou análoga e/ou em } \\
\text { situação de risco de aliciamento, bem como } \\
\text { favorecer o acesso desses trabalhadores em } \\
\text { atividades de geração de trabalho e renda, } \\
\text { baseado na livre associação de } \\
\text { trabalhadores, nos princípios de } \\
\text { autogestão e cooperação. }\end{array}$ & $\begin{array}{l}\text { Egressos do T.E. } \\
\text { e/ou em situação } \\
\text { de } \\
\text { vulnerabilidade. }\end{array}$ \\
\hline $\begin{array}{l}\text { De olho aberto para } \\
\text { não virar escravo }\end{array}$ & $\begin{array}{l}\text { Comissão } \\
\text { Pastoral da } \\
\text { Terra }\end{array}$ & $\begin{array}{l}\text { Visa articular estratégias de trabalho a fim } \\
\text { de prevenir e combater o trabalho escravo, } \\
\text { a princípio nos Estados de Maranhão, } \\
\text { Tocantins, Pará e Mato Grosso. Visa à } \\
\text { denúncia das violações dos direitos dos } \\
\text { trabalhadores da terra, através de uma boa } \\
\text { capilaridade por parte de uma rede } \\
\text { consistente de agentes treinados e } \\
\text { motivados, bem como a defesa das vítimas } \\
\text { destas violações estão apoiadas em } \\
\text { material didático especialmente realizado } \\
\text { pela campanha. }\end{array}$ & $\begin{array}{l}\text { Trabalhado-res } \\
\text { Rurais }\end{array}$ \\
\hline
\end{tabular}

Brasiliana - Journal for Brazilian Studies. Vol. 2, n.2 (Nov 2013). ISSN 2245-4373. 